This manuscript is a preprint and has been submitted to Geology. It has not undergone peerreview. Subsequent versions of this manuscript may have different content as a result of the review process. If accepted, the final version of this manuscript will be available via the 'Peerreviewed Publication DOI' link on the right-hand side of this webpage. We welcome feedback, so please feel free to contact any of the authors directly or by leaving a comment. 


\section{A snapshot of the earliest stages of normal fault development}

3 Ahmed Alghuraybi ${ }^{1}$, Rebecca E. Bell ${ }^{1}$, and Christopher A-L. Jackson ${ }^{2}$

4

$5 \quad{ }^{1}$ Basins Research Group (BRG), Earth Science and Engineering, Imperial College, Prince

6 Consort Road, London, SW7 2BP, UK

$7 \quad{ }^{2}$ Department of Earth, Atmospheric and Environmental Sciences, The University of Manchester,

8 Williamson Building, Oxford Road, Manchester, M13 9PL, UK

10 ABSTRACT

11 Despite decades of study, models for the growth of normal faults lack a temporal

12 framework within which to understand how these structures accumulate displacement and

13 lengthen through time. Here, we use borehole and high-quality 3D seismic reflection data from

14 offshore Norway to quantify the lateral $\left(0.2-1.8 \mathrm{mmyr}^{-1}\right)$ and vertical $\left(0.004-0.02 \mathrm{mmyr}^{-1}\right)$

15 propagation rates (averaged over 12-44 Myr) for several long (up to $43 \mathrm{~km}$ ), moderate

16 displacement (up to $225 \mathrm{~m}$ ) layer-bound faults that we argue provide a unique, essentially

17 'fossilised' snapshot of the earliest stage of fault growth. We show that lateral propagation rates

18 are 90 times faster than displacement rates during the initial $25 \%$ of their lifespan suggesting that

19 these faults lengthened much more rapidly than they accrued displacement. Although these faults

20 have slow displacement rates compared with data compiled from 30 previous studies, they have

21 comparable lateral propagation rates. This suggests that the unusual lateral propagation to

22 displacement rate ratio is likely due to fault maturity, which highlights a need to document both 
23 displacement and lateral propagation rates to further our understanding of how faults evolve

24 across various temporal and spatial scales.

\section{INTRODUCTION}

There are currently two end-member fault growth models: (i) the 'propagating fault

28 model' and (ii) the 'constant length model'. The former arises from the apparent scaling

29 relationship between maximum fault displacement $\left(\mathrm{D}_{\max }\right)$ and length $\left(\mathrm{L}_{\max }\right)$ and proposes that

30 faults grow by simultaneously accumulating length and displacement (where $\mathrm{D}_{\max } / \mathrm{L}_{\max }$ typically

31 ranges between 1 - 0.01; e.g., Watterson, 1986; Walsh and Watterson, 1988; Cowie and Scholz,

32 1992; Schlische et al., 1996; Walsh et al., 2003). However, global Dmax-Lmax datasets show a

33 high degree of scatter (e.g., Rotevatn et al., 2019), which may reflect, for example, differences in

34 the geological setting within which the studied fault network formed, or uncertainties in

35 measuring the key geometric parameters due to seismic imaging quality or outcrop extent (e.g.,

36 Walsh and Watterson, 1988; Gillespie et al., 1992; Kim and Sanderson, 2005). An alternative

37 interpretation is that this variability results from fault maturity, related to the fact that some faults

38 may attain their near-final lengths before accumulating significant displacement (i.e., the

39 constant-length fault model; e.g., Walsh et al., 2002; Meyer et al., 2002; Nicol et al., 2005; Nicol

40 et al., 2016; Childs et al., 2017; Rotevatn et al., 2019). Regardless of the precise mode of growth,

41 previous studies have shown that strong mechanical anisotropy in the faulted, horizontally

42 layered host rock can restrict the vertical propagation of faults (e.g., Nicol et al., 1996; Soliva et

43 al., 2005; Roche et al., 2013). Faults forming in these rocks may have anomalously high fault

44 aspect ratios (i.e., 3 - 13, compared to $1-3$ for more typical faults) and strikingly low D-L 
45 scaling relationships (i.e., $\mathrm{D}_{\max } / \mathrm{L}<0.01$ ) (e.g., Nicol et al., 1996; Schlische et al., 1996; Soliva et 46 al., 2005; Roche et al., 2013).

47 The rate at which faults lengthen and accumulate displacement is a key element of their 48 kinematic history and influences the role they play in controlling the geomorphology, seismic 49 hazard, and resource potential of rift basins (e.g., Walsh et al., 2003). Depending on the period 50 and type of observation, displacement rates vary. For example, over relatively short

51 observational periods (10s years), GPS/geodetic data show that displacement rates can be

52 relatively fast (>10 $\left.\mathrm{mm} \mathrm{yr}^{-1}\right)$ and highly variable (e.g., Briole et al., 2000; Wallace et al., 2014)

53 compared to longer-period, typically more stable geological slip rates $\left(<1 \mathrm{~mm} \mathrm{yr}^{-1}\right)$ derived from

54 seismic reflection or field data (e.g., Cowie et al., 2012; Mouslopoulou et al., 2012). In contrast,

55 lateral propagation rates are less frequently reported in fault growth studies especially over short 56 observational periods. Our current understanding of fault growth, in particular how changes in

57 fault geometry relate to fluctuations in displacement rate, remains uncertain. For example, fault

58 growth models need to quantify both lateral and displacement rates to provide a temporal

59 framework of fault growth (e.g., Walsh et al., 2002; Rotevatn et al., 2019), given this may

60 reconcile the differences between short-term geodetic rates and long-term geological rates.

61 Constraining the patterns and rates of fault growth requires the analysis of syn-kinematic strata

62 (i.e., strata deposited whilst the fault is active), although this is commonly poorly imaged in

63 seismic reflection data or not preserved in the field (e.g., Rotevatn et al., 2019).

64 We here use age-constrained, high-quality 3D seismic reflection and borehole data to

65 determine the lateral and vertical propagation rates for several layer-bound faults that: (i) exhibit

66 unusually high (up to 25) aspect ratios; (ii) have anonymously low (c. 0.001) $\mathrm{D}_{\max }-\mathrm{L}_{\max }$ scaling

67 relationships; and (iii) were associated with continuous, strike-elongate depocenters during the 
68 very earliest stages of their development, all features consistent with the constant-length model.

69 We propose that these faults provide a unique snapshot of the earliest stage of fault growth.

\section{GEOLOGICAL SETTING}

The study area is in the SW Barents Sea (Fig. 1A), offshore northern Norway where

73 multiple phases of rifting, including one in the Middle Jurassic to Early Cretaceous that formed

74 the faults studied here, shaped the large-scale structure of the region (e.g., Faleide et al., 2008).

75 The tectonic (i.e., non-gravitational) origin of the studied fault system is supported by the fact

76 that they: (i) strike perpendicular to the NNW-SSE extension direction associated with Middle

77 Jurassic to Early Cretaceous rifting; and (ii) the basal detachment is not tilted in the direction of

78 fault dip. The faults developed in Triassic to Lower Cretaceous clastic rocks deposited on

79 Caledonian crystalline basement (e.g., Doré, 1995). The faulted host rock is characterized by

80 strong mechanical competency contrast between alternating intervals of relatively weak,

81 mudstone-rich strata (i.e., Upper Permian) and mechanically stronger, siltstone- and sandstone-

82 rich layers (i.e., Triassic) (Fig. 1B).

83

84 DATA AND METHODS

85

86 Geometric analysis

87 We use pre-stack time-migrated 3D seismic reflection data covering c. $533 \mathrm{~km}^{2}$ and with 88 an estimated vertical resolution $=12.5-25 \mathrm{~m}$ in the depth range of interest (see Appendix 1).

89 These data allow us to map and describe the plan-view and cross-sectional geometry of the

90 studied fault network, and by collecting throw data for nine horizons (six age-constrained by 
91 well data and three of unknown age that mark distinct changes in seismic facies) to show how

92 throw varies across the fault surfaces (Fig. 1B). The horizons' ages were constrained by wellbore

93 7124/4-1S. We also produce isochron (time-thickness) maps, throw strike-projections, and

94 expansion index (EI) analysis to further describe the geometry of the fault network and critically

95 assess associated variations in the thickness of syn-kinematic strata (see review by Walsh and

96 Watterson, 1991 and Jackson et al., 2017).

97

$98 \quad$ Kinematic analysis

99 We estimate the lateral fault tip propagation rate by taking the fault half-length as

100 measured at the base of the syn-kinematic interval and dividing it by the time interval to the next

101 age-constrained horizon that shows across-fault thickening (i.e., we establish the duration and

102 length of major depocenter development and calculate the bi-directional propagation rate of the

103 fault tips; cf. Childs et al., 2003). Similarly, we calculate the displacement rate by dividing the

104 maximum displacement by the time interval to the next age-constrained horizon (e.g., Nicol et

105 al., 1997; Bell et al., 2009). We provide detailed descriptions of our methods in Appendix 2.

106

107 RESULTS

108

109 Fault network geometry

110 The studied fault network consists of 15 Late Jurassic faults offsetting Early Triassic to

111 Early Cretaceous stratigraphy (Fig. 1B, C). Most of these faults tip-out downwards in mudstone-

112 dominated, Permian strata, die-out upwards into Late Jurassic - Early Cretaceous strata, and are

113 associated with Upper Jurassic growth strata (i.e., they were active in the Late Jurassic; Fig. 1B). 
114 These faults are not associated with clear fault bends, abandoned splays or relays (Fig. 1C). The

115 majority of these faults are unusual in that they are: i) notably under-displaced with respect to

116 their lengths $\left(\mathrm{D}_{\max } / \mathrm{L}_{\max }=\right.$ c. $0.001 ;$ Fig. $\left.1 \mathrm{~A}\right)$; and ii $)$ have anomalously high aspect ratios $(>13$;

117 Fig. 1D). Here, we present a detailed geometric analysis of two faults from the fault network; not

118 only do these have the highest aspect ratios, but they are also particularly large and thus well-

119 imaged.

120

$121 \quad$ Fault 8 (F8) - Observations

122 F8 is the longest fault in the network (c. $43 \mathrm{~km}$; Fig. 1C). It has a maximum throw of c.

$12372 \mathrm{~ms}$ (c. $110 \mathrm{~m}$; see velocity models in Appendix 3) and a maximum total displacement of c.

$124130 \mathrm{~m}$ (Fig. 2A). F8 strikes E-W, dips to the N, and has the highest aspect ratio of any fault in

125 the network (c. 24.6; Fig. 1). F8 appears to have multiple along-strike throw maxima, all of

126 which are located at the base of the syn-kinematic interval (i.e., base Upper Jurassic; Fig. 2A).

127 Upper Jurassic strata thicken across the fault (EI up to 2.2), with a key observation being that the

128 lowermost reflections in this package onlap onto the base syn-kinematic horizon immediately

129 adjacent to the fault tips (H4) (Fig. 2).

131 Fault 11 (F11) - Observations

132 F11 is an E-W striking, N-dipping fault that is c. $31 \mathrm{~km}$ long (Fig. 1C). It has a maximum 133 throw of c. $55 \mathrm{~ms}(\mathrm{c} .70 \mathrm{~m}$ ) and a maximum total displacement of c. $104 \mathrm{~m}$ (Fig. 2A). F11 has an 134 aspect ratio of c. 19 with Upper Jurassic strata thickening across the fault (EI values up to 1.7;

135 Fig. 2A, B). Similar to F8, F11 appears to bound a single, strike-elongate, Upper Jurassic

136 depocenter (Fig. 2B). However, F11 exhibits a broad, bell-shaped throw-length profile at the 
137 base syn-kinematic level (H4), with its throw maximum skewed towards the west (Figs. 2A). A

138 key observation is that Upper Jurassic growth strata clearly thicken across the fault just inboard 139 of its tips (Fig. 2B, C).

140

141 Interpretation

142 Growth strata show that F8 and F11 were active from 201.3 - 157.3 Ma (i.e., in the Late

143 - Early Jurassic; Fig. 2B), with the presence of multiple throw maxima on some of these faults

144 (F8; Fig. 2A) providing geometric evidence that they grew by segment linkage (e.g., Cartwright

145 et al., 1995). However, the lack of obvious bends, breached relays, or abandoned splays suggests

146 that the precursor segments did not overlap, and may have formed part of a single, kinematically

147 linked structure from their inception (e.g., Childs et al., 2017). This is supported by the fact that

148 the thickening we observe here is seen along-strike of the faults and is associated with onlap of

149 the lowermost syn-kinematic strata onto pre-kinematic immediately inboard of the lateral fault

150 tips (Fig. 2B, C).

151

152 GROWTH RATES OF FAULTS

153 The studied faults have relatively slow slip rates $\left(0.0009-0.004 \mathrm{~mm} / \mathrm{yr}^{-1}\right)$ when averaged

154 over the $44 \mathrm{Myr}$ period of fault activity. However, by assuming a constant sedimentation rate, we 155 can estimate the age of the earliest stage of fault activity, or the age at which the near-final fault

156 length was established, that is associated with the development of the strike-elongate depocenters

157 (Fig. 2B). By using this estimated age (12 Myr), we infer displacement rates of (0.004-0.02 mm

$158 \mathrm{yr}^{-1}$ ) for the earliest detectable stage of fault activity. We then compare these slip rates with data

159 from 29 other datasets (see Appendix 4 for a full list of references), showing the studied fault 
160 network having relatively low slip rates even when averaged over the estimated 12 Myr period

161 (Fig. 3A). Even though our slip rates are relatively low, they are similar to rates measured over

162 similar time scales (i.e., >107 years; Fig. 3A) in the North Sea (Nicol et al., 1997; Bell et al.,

163 2014), the Timor Sea (Meyer et al., 2002), the Basin \& Range and Taranaki Rift (Mouslopoulou

164 et al., 2009), or for faults with similar trace lengths (>104 km; Fig. 3B; Lathrop et al., 2021).

165 Despite having low displacement rates, the studied fault network is associated with high

166 lateral propagation rates $(0.2-1.8 \mathrm{~mm} /$ year $)$ that are 1-2 orders-of-magnitude higher than other

167 faults active over similar durations (i.e., >106 years; Fig. 3A) (Bell et al., 2014; Lathrop et al.,

168 2021). By taking the ratio between lateral and vertical propagation rates (i.e., to quantify the

169 difference between lateral and vertical deformation), we observe that independent of fault length

170 (and accuracy of our age estimate of $12 \mathrm{Myr}$ ), the studied faults propagated laterally much more

171 rapidly (i.e., 90 times faster) than they accumulated displacement (see Appendix 5), a value 2-3

172 orders of magnitude higher than other seismically imaged faults of similar length (e.g., Bell et

173 al., 2009; Lathrop et al., 2021). This observation suggests that the studied network captures faults

174 during their very earliest stage of development, when they were growing in accordance with the

175 constant-length model. They had rapidly lengthened and reached their near-final lengths but did

176 not have a chance to accumulate significant additional displacement before becoming inactive

177 (e.g., Walsh et al., 2002; Meyer et al., 2002; Nicol et al., 2005; Nicol et al., 2016; Childs et al.,

178 2017). Why the faults became inactive is unknown, although we suspect this is related to strain

179 localization on to the nearby, very large (c. $2 \mathrm{~km}$ displacement), basement-rooted, Troms-

180 Finnmark Fault Complex (TFFC), which continued to be active until the Eocene (e.g.,

181 Alghuraybi et al., 2021). This effect of strain localization is amplified by virtue of having a weak

182 mudstone layer at the bottom of the faulted interval, which inhibited downward propagation of 
183 these faults and limited the accumulation of additional displacement. As a result, these faults

184 have large aspect ratios and were characterized by lateral propagation rates that were

185 significantly faster than displacement rate.

186 The highest aspect ratio ever reported for a natural normal fault is 12 (Nicol et al., 1996;

187 Soliva et al., 2005; Roche et al., 2013); this is significantly lower than the highest aspect ratio we

188 observe here (c. 25). In fact, five of the studied faults have aspect ratios >>13 (Fig. 1D).

189 Numerical models, motivated by observations from meter-scale fault networks in layered

190 carbonate rocks, show that aspect ratios can vary through time, increasing when the faults

191 interact with layers that restrict their onwards vertical propagation, before decreasing again when

192 they are able to breach those layers (e.g., Soliva et al., 2005; Roche et al., 2013). Our study

193 suggests that this process may occur at substantially larger scales than previous reported,

194 meaning aspect ratio variability is a fundamental aspect of fault growth across scales in

195 mechanically layered rocks.

196 Our slip rate data compilation builds on previous works (e.g., Nicol et al., 2005;

197 Mouslopoulou et al., 2009; Nicol et al., 2020) and includes lateral propagation and displacement

198 rate data measured over a range of temporal scales using different methods (geodetic, GPS, field

199 observations, seismic refraction, and reflection data). Our updated database shows a high degree

200 of scatter for slip rates over timescales $>10^{5}$ years, which could simply reflect the fact that more

201 data has been collected over these longer timescales. It is also clear from our dataset that lateral

202 propagation rates are often not reported or less frequently documented compared to displacement

203 rates. Based on this we argue there is a need to collect more data measured over shorter temporal

204 scales (i.e., especially $10^{2}-10^{5}$ years) and to document, where possible, both displacement and 
205 lateral propagation rates. By doing so, we can further our understanding of how faults evolve

206 across various temporal and spatial scales.

207

208 ACKNOWLEDGEMENT

209 The results presented here are part of AA's PhD research at Imperial College London, funded by

210 Saudi Aramco. We thank the Norwegian Petroleum Directorate the publicly data

211 (https://portal.diskos.cgg.com/whereoil-data/) and Schlumberger for Petrel software.

212

\section{FIGURE CAPTIONS}

214 Figure 1: (A) Map showing study area location and displacement - length data from the studied

215 fault network plotted on a global displacement-length plot modified from Rotevatn et al. (2019).

216 (B) A representative seismic cross-section highlighting the geometry of the studied faults and

217 horizon's age and lithology as constrained by wellbore 7124/4-1S. (C) A time-structure map of

218 the base syn-kinematic unit (H4) with a white-dashed line indicating the location of the seismic

219 section in (B). (D) Aspect ratio (length/height) distribution of the studied fault network with

220 dashed-horizontal lines showing average aspect ratios of "blind isolated normal faults in layered

221 sequences" (yellow), maximum aspect ratio of restricted faults (red) (Nicol et al., 1996) and

222 maximum aspect ratio for faults cutting formations with strong mechanical contrast (green)

223 (Roche et al., 2013).

224 Figure 2: (A) Strike-projected throw distributions and Expansion Index values along Faults 8

225 and 11. (B) Isochron (time-thickness) maps for syn-kinematic unit (1) and lowermost package of

226 that unit (2) showing across-fault thickening in the smallest resolvable interval. (C) un- 
227 interpreted and interpreted seismic sections along-strike of Fault 8 with a red arrow highlighting

228 the observed onlap relationship.

229 Figure 3: (A) slip rate data across various timescales for the studied fault network (cross) and

230 literature data (circle). Vertical slip rate is shown in blue while lateral propagation rate is shown

231 in green. Error-bars account for uncertainty in age-constrain (10-44 Myr). Another version of

232 this plot is provided in Appendix 4 where each literature study is clearly indicated, and the

233 literature data is provided in Appendix 6. (B) slip rate data across various fault lengths.

\section{REFERENCES}

236 Alghuraybi, A., Bell, R. E., \& Jackson, C. A.-L., 2021, The geometric and temporal evolution of 237 fault-related folds constrain normal fault growth patterns, Barents Sea, offshore Norway:

238 Basin Research, v.00, p. 1-22, https://doi.org/10.1111/bre.12633

239 Bell, R. E., Jackson, C. A. L., Whipp, P. S., \& Clements, B., 2014, Strain migration during multiphase extension: Observations from the northern North Sea: Tectonics, v. 33, p.

242 Bell, R. E., McNeill, L. C., Bull, J. M., Henstock, T. J., Collier, R. L., \& Leeder, M. R., 2009,

Briole, P., Rigo, A., Lyon-Caen, H., Ruegg, J. C., Papazissi, K., Mitsakaki, C., ... \& Deschamps, Fault architecture, basin structure and evolution of the Gulf of Corinth Rift, central A., 2000, Active deformation of the Corinth rift, Greece: results from repeated Global Positioning System surveys between 1990 and 1995: Journal of Geophysical Research:

249 Cartwright, J. A., Trudgill, B. D., \& Mansfield, C. S., 1995, Fault growth by segment linkage: an 
explanation for scatter in maximum displacement and trace length data from the https://doi.org/10.1016/0191-8141(95)00033-A

253 Childs, C., Nicol, A., Walsh, J. J., \& Watterson, J., 2003, The growth and propagation of

Doré, A. G., 1995, Barents Sea Geology, Petroleum Resources and Commercial Potential:

Childs, Conrad, Holdsworth, R. E., Jackson, C. A. L., Manzocchi, T., Walsh, J. J., \& Yielding, synsedimentary faults: Journal of Structural geology, v. 25, p. 633-648.

G., 2017, Introduction to the geometry and growth of normal faults: Geological Society Special Publication, v. 439, p. 1-9, https://doi.org/10.1144/SP439.24

Cowie, P. A., \& Scholz, C. H., 1992, Displacement-length scaling relationship for faults: data synthesis and discussion: Journal of Structural Geology, v. 14, p. 1149-1156.

Cowie, P. A., Roberts, G. P., Bull, J. M., \& Visini, F., 2012, Relationships between fault geometry, slip rate variability and earthquake recurrence in extensional settings: Geophysical Journal International, v. 189, p. 143-160. Arctic, v. 48, p. 207-221, http://www.jstor.org/stable/40511656

Faleide, J. I., Tsikalas, F., Breivik, A. J., Mjelde, R., Ritzmann, O., Engen, Ø., Wilson, J., \& Eldholm, O., 2008, Structure and evolution of the continental margin off Norway and the Barents Sea: Episodes, v. 31, p. 82-91, https://doi.org/10.18814/epiiugs/2008/v31i1/012

Gillespie, P. A., Walsh, J. T., \& Watterson, J., 1992, Limitations of dimension and displacement data from single faults and the consequences for data analysis and interpretation: Journal of Structural Geology, v. 14, p. 1157-1172.

271 Jackson, Christopher A.L., Bell, R. E., Rotevatn, A., \& Tvedt, A. B. M., 2017, Techniques to determine the kinematics of synsedimentary normal faults and implications for fault 
growth models: Geological Society Special Publication, v. 439, p. 187-217, https://doi.org/10.1144/SP439.22

275

276

277

278

279

280

281

282

283

284

285

286

287

288

289

290

291

292

293

294

295

Kim, Y. S., \& Sanderson, D. J., 2005, The relationship between displacement and length of faults: a review: Earth-Science Reviews, v. 68, p. 317-334.

Lathrop, B. A., Jackson, C. A.-L., Bell, R. E., \& Rotevatn, A., 2021, Normal fault kinematics and the role of lateral tip retreat: An example from offshore NW Australia: Tectonics, v. 40, e2020TC006631, https://doi. org/10.1029/2020TC006631

Meyer, V., Nicol, A., Childs, C., Walsh, J. J., \& Watterson, J., 2002, Progressive localisation of strain during the evolution of a normal fault population: Journal of Structural Geology, v. 24, p. 1215-1231, https://doi.org/10.1016/S0191-8141(01)00104-3.

Mouslopoulou, V., Walsh, J. J., \& Nicol, A., 2009, Fault displacement rates on a range of timescales: Earth and Planetary Science Letters, v. 278, p. 186-197, https://doi.org/10.1016/j.eps1.2008.11.031

Mouslopoulou, V., Nicol, A., Walsh, J. J., Begg, J. G., Townsend, D. B., \& Hristopulos, D. T., 2012, Fault-slip accumulation in an active rift over thousands to millions of years and the importance of paleoearthquake sampling: Journal of Structural Geology, v. 36, p. 71-80, https://doi.org/10.1016/j.jsg.2011.11.010

Nicol, A., Watterson, J., Walsh, J. J., \& Childs, C., 1996, The shapes, major axis orientations and displacement patterns of fault surfaces: Journal of Structural Geology, v. 18, p. 235-248, https://doi.org/10.1016/S0191-8141(96)80047-2

Nicol, A., Walsh, J. J., Watterson, J., \& Underhill, J. R., 1997, Displacement rates of normal faults: Nature, v. 390, p. 157-159, https://doi.org/10.1038/36548

Nicol, A., Walsh, J. J., Manzocchi, T., \& Morewood, N., 2005, Displacement rates and average 
earthquake recurrence intervals on normal faults: Journal of Structural Geology, v. 27, p. 541-551, https://doi.org/10.1016/j.jsg.2004.10.009

298 Nicol, A., Robinson, R., Van Dissen, R. J., \& Harvison, A., 2016, Variability of recurrence

Nicol, A., Mouslopoulou, V., Begg, J., \& Oncken, O., 2020, Displacement accumulation and sampling of paleoearthquakes on active normal faults of Crete in the eastern Mediterranean: Geochemistry, Geophysics, Geosystems, v. 21, e2020GC009265, https://doi. org/10.1029/2020GC009265

Roche, V., Homberg, C., \& Rocher, M., 2013, Fault nucleation, restriction, and aspect ratio in layered sections: Quantification of the strength and stiffness roles using numerical modeling: Journal of Geophysical Research: Solid Earth, v. 118, p. 4446-4460, doi:10.1002/jgrb.50279

Rotevatn, A., Jackson, C. A. L., Tvedt, A. B., Bell, R. E., \& Blækkan, I., 2019, How do normal faults grow?: Journal of Structural Geology, v. 125, p. 174-184, https://doi.org/10.1016/j.jsg.2018.08.005

Schlische, R. W., Young, S. S., Ackermann, R. V., \& Gupta, A., 1996, Geometry and scaling relations of a population of very small rift-related normal faults: Geology, v. 24, p. 683686, https://doi.org/10.1130/0091-7613(1996)024<0683:GASROA>2.3.CO;2

Soliva, R., \& Benedicto, A., 2005, Geometry, scaling relations and spacing of vertically restricted normal faults: Journal of Structural Geology, v. 27, p. 317-325, https://doi.org/10.1016/j.jsg.2004.08.010 
319 Wallace, L. M., Ellis, S., Little, T., Tregoning, P., Palmer, N., Rosa, R., ... \& Kwazi, J., 2014,

320 Continental breakup and UHP rock exhumation in action: GPS results from the Woodlark

321 Rift, Papua New Guinea: Geochemistry, Geophysics, Geosystems, v. 15, p. 4267-4290,

322 https://doi.org/10.1002/2014GC005458

323 Walsh, J. J., \& Watterson, J., 1988, Analysis of the relationship between displacements and

324 dimensions of faults: Journal of Structural geology, v. 10, p. 239-247,

325 https://doi.org/10.1016/0191-8141(88)90057-0

326 Walsh, J. J., \& Watterson, J., 1991, Geometric and kinematic coherence and scale effects of normal fault systems. in Roberts, A. M., Yielding, G., Freemen, B., eds., The Geometry

Walsh, J. J., Bailey, W. R., Childs, C., Nicol, A., \& Bonson, C. G., 2003, Formation of segmented normal faults: A 3-D perspective: Journal of Structural Geology, v. 25, p. 1251-1262, https://doi.org/10.1016/S0191-8141(02)00161-X

Walsh, J. J., Nicol, A., \& Childs, C., 2002, An alternative model for the growth of faults: Journal of Structural Geology, v. 24, p. 1669-1675, https://doi.org/10.1016/S01918141(01)00165-1

336 Watterson, J., 1986, Fault dimensions, displacements and growth: Pure and Applied Geophysics, v. 124, p. 365-373, https://doi.org/10.1007/BF00875732 
(A)

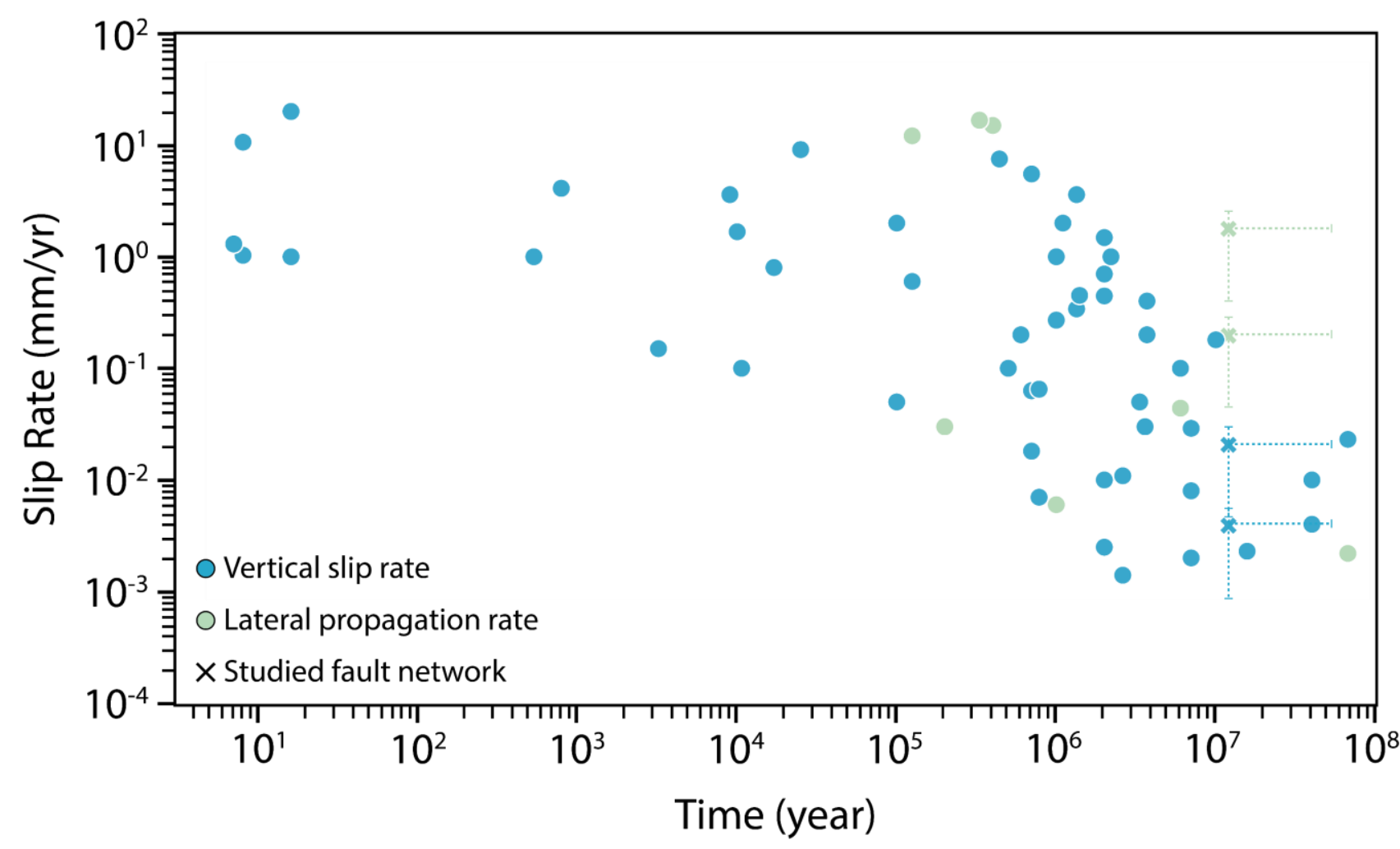

(B)

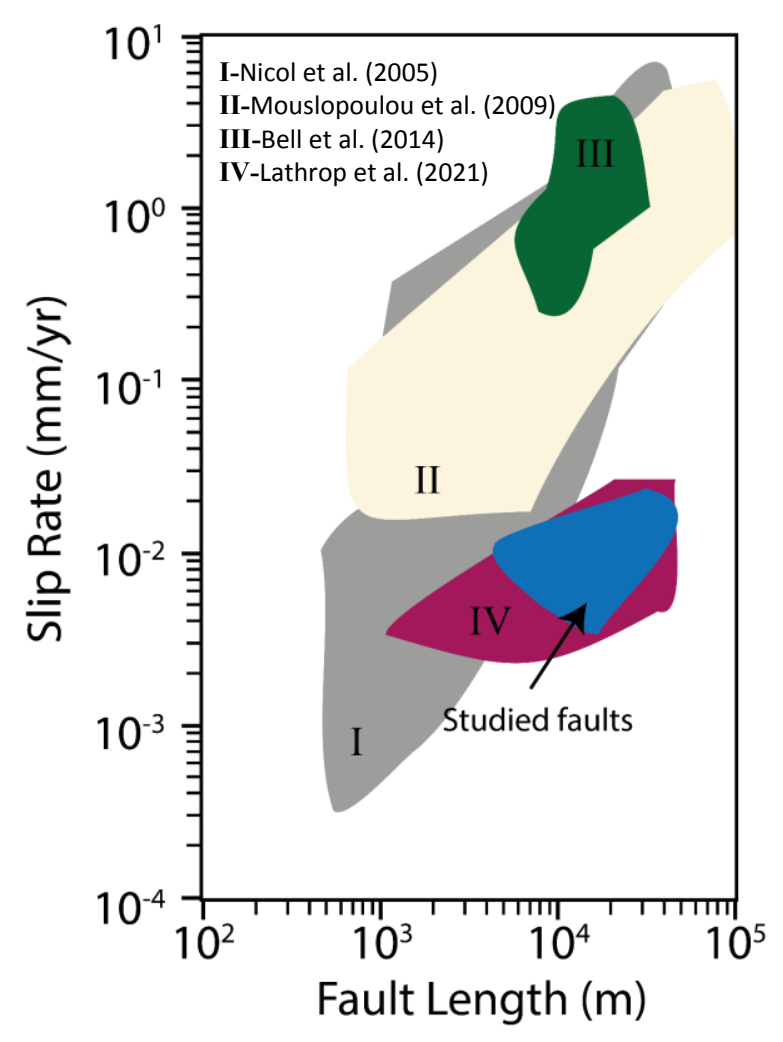




\section{Appendix 1}

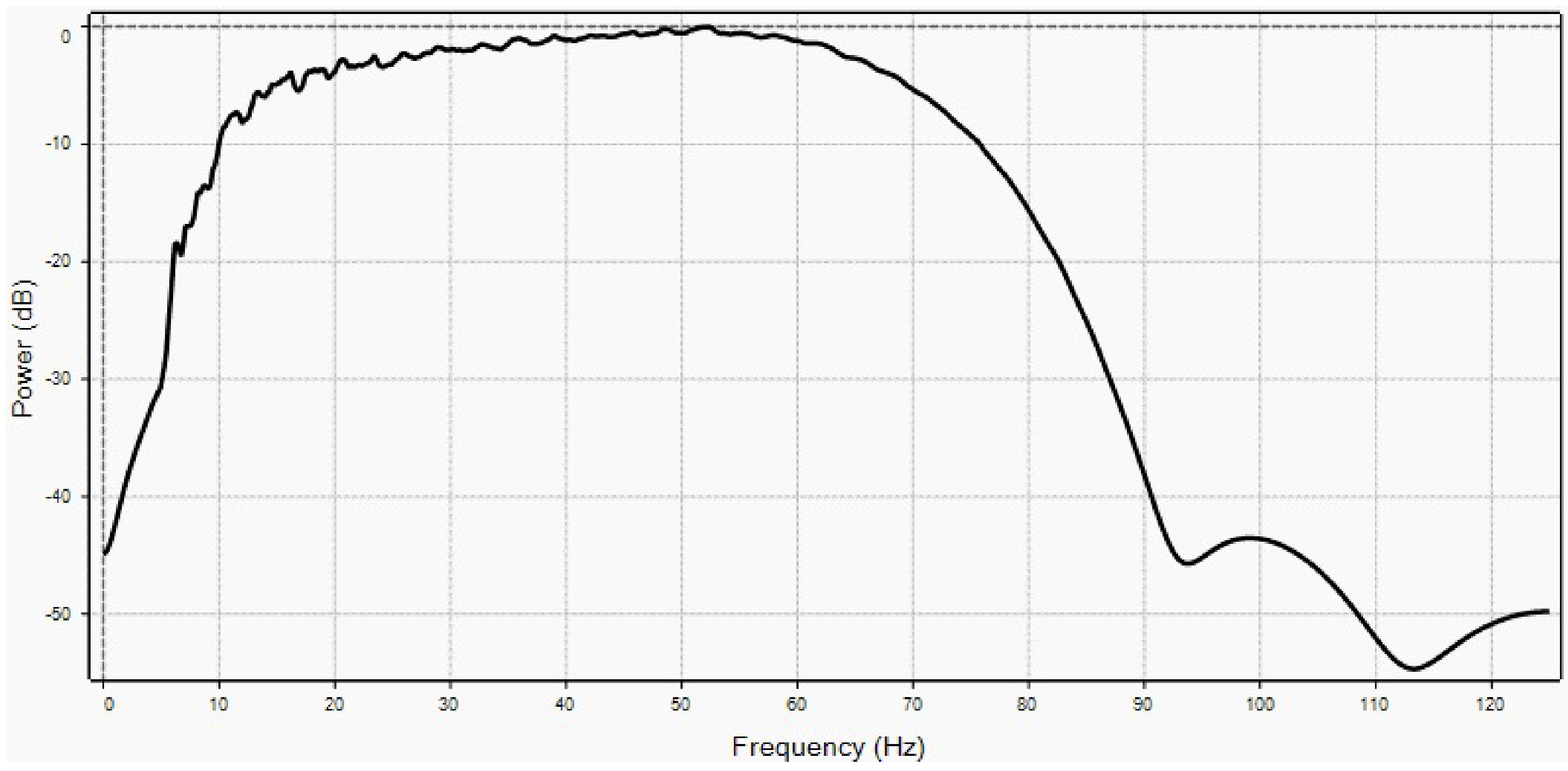

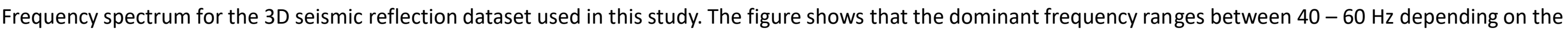
depth interval within the seismic survey. 
Appendix 2 - detailed description of the methodology we use to calculate fault throw, displaccement, vertical slip and lateral propagation rates along with fault length/height aspect ratio

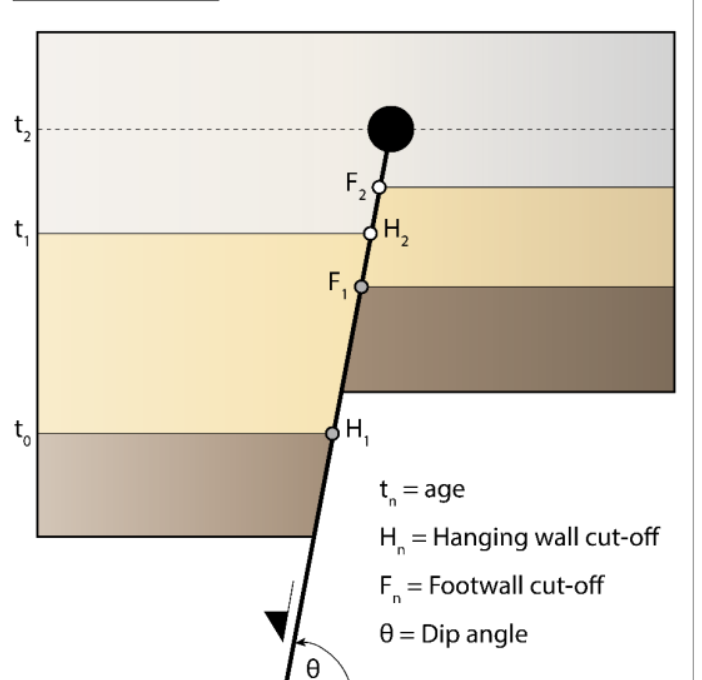

Throw $_{n}=H_{n}-F_{n}$

Displacement $_{n}=\frac{H_{n}-F_{n}}{\operatorname{Sin} \theta}$

Slip Rate ${ }_{t 0: 11}=\frac{\text { Displacement } t_{1} \text { - Displacement } t_{2}}{t_{0}-t_{1}}$

Slip Rate ti-12 $_{1}=\frac{\text { Displacement }_{2}}{t_{1}-t_{2}}$

Half Length $=x_{1}-x_{0} ;$ Half Length $_{2}=x_{2}-x_{1}$

Propagation Rate $_{1}=\frac{\text { Half Length }}{t_{0}-t_{1}}$

Propagation Rate $e_{2}=\frac{\text { Half Length }}{t_{1}-t_{2}}$

Aspect Ratio $=\frac{\text { Length }}{\text { Heigth }}$

ii) Map-view

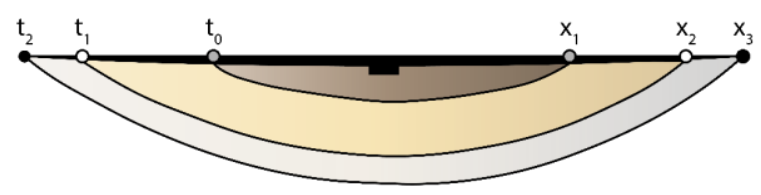

iii) Displacement-length profile

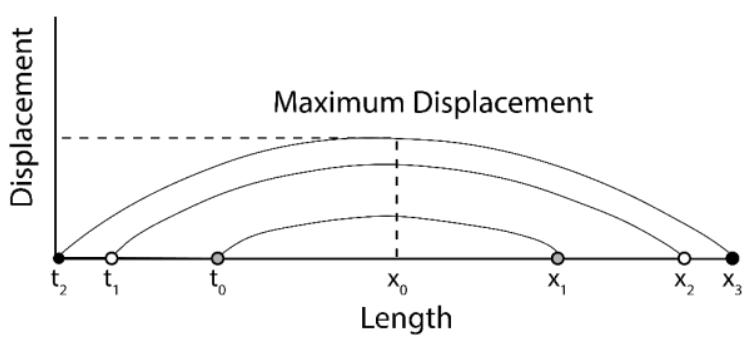

iv) Strike-projection

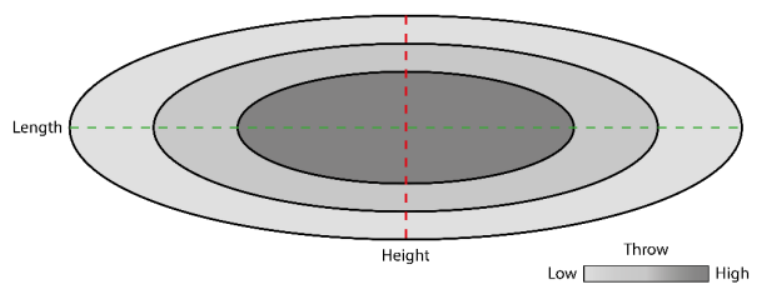




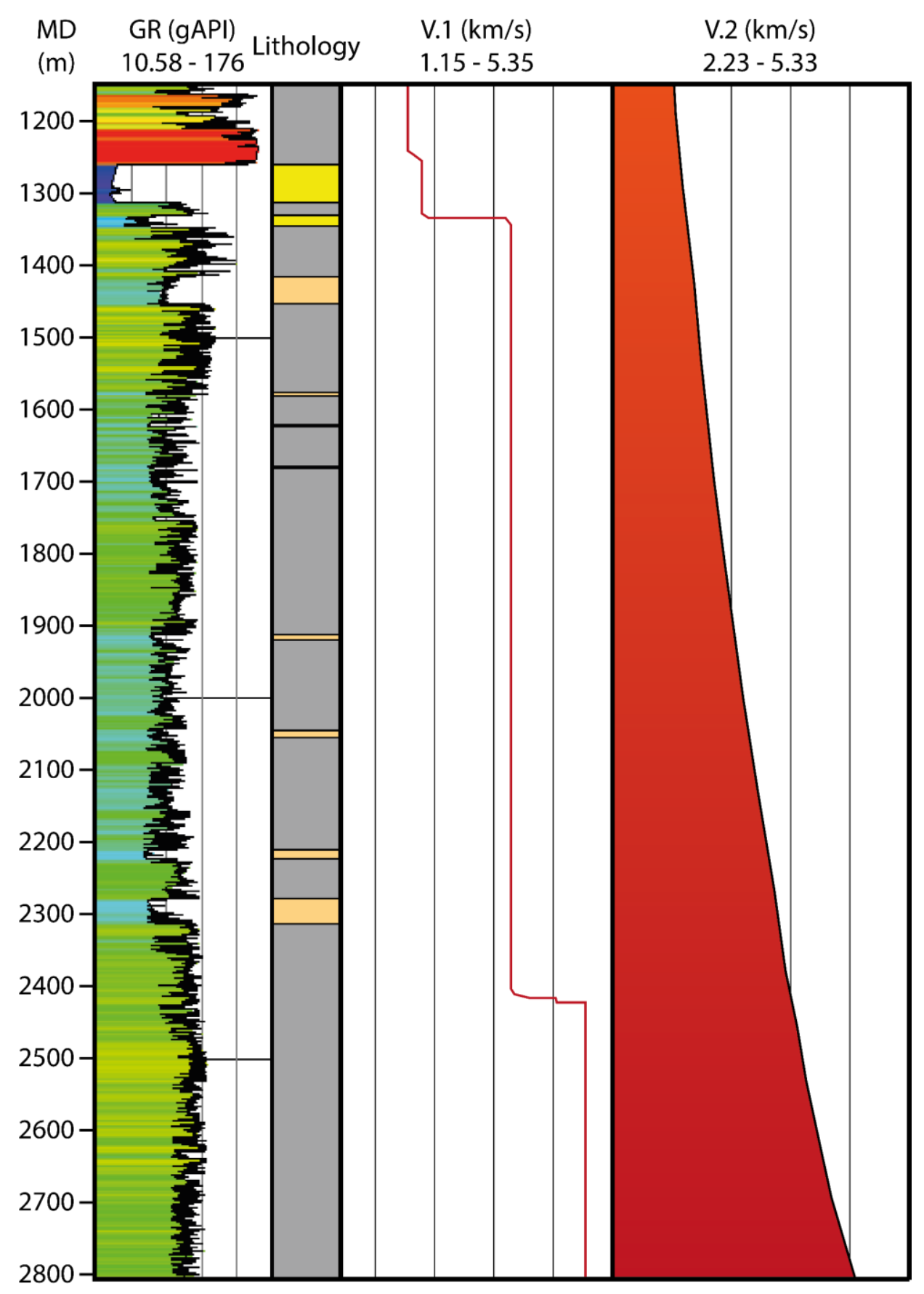

Appendix 3

Well section view showing wireline and calculated logs for wellbore 7124/4-1S. The displayed data are for gamma

ray (GR), interpreted lithology from GR, modelled interval velocity using simplified geological model (V.1),

calculated pseudo interval velocity using estimated time - depth relationship from seismic well tie (V.2). 


\section{Appendix 4}

A plot showing the compiled data from 29 different studies in addition to data from the current study. Detailed information about each study are provided in Appendix 6 .

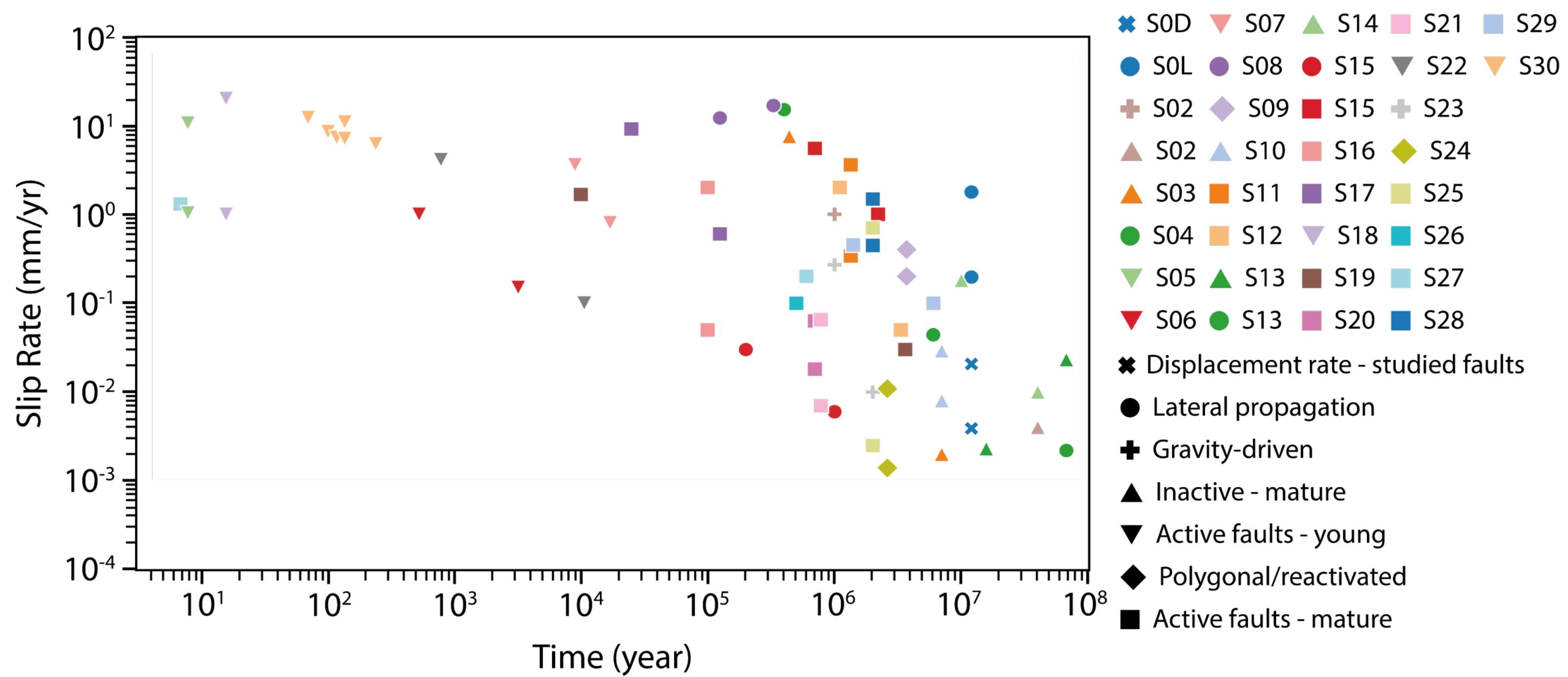


Appendix 5

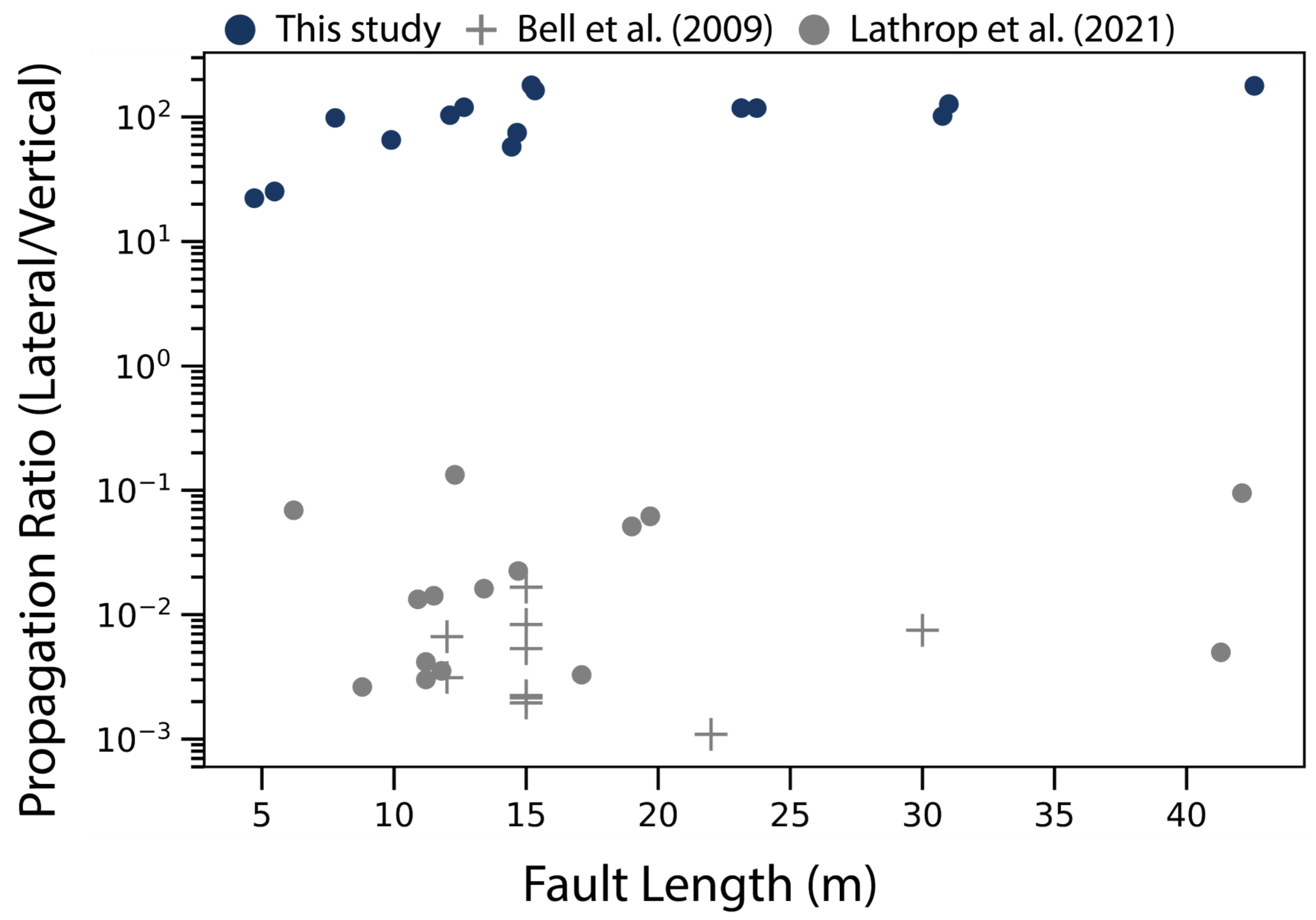

